\section{(A) Check for updates}

Cite this: Dalton Trans., 2022, 51 4675

Received 4th November 2021 Accepted 31st January 2022

DOI: $10.1039 / \mathrm{d} 1 \mathrm{dt} 03737 \mathrm{~d}$

rsc.li/dalton

\title{
Influence of Fe-clustering on the water oxidation performance of two-dimensional layered double hydroxides $\uparrow$
}

\author{
Alvaro Seijas-Da Silva, (D) † Víctor Oestreicher, (D) $\ddagger$ Eugenio Coronado (D) and \\ Gonzalo Abellán (D) *
}

\begin{abstract}
Among the two-dimensional (2D) materials family, layered double hydroxides (LDHs) represent a key member due to their unparalleled chemical versatility. In particular, Fe-based LDHs are distinguished candidates due to their high efficiency as oxygen evolution reaction (OER) electrocatalysts. Herein, we have selected MgFe-based LDH phases as model systems in order to decipher whether Fe-clustering exerts an effect on the OER performance. For that, we have optimized hydrothermal synthesis by using triethanolamine (TEA) as the chelating agent. The magnetic characterisation allows us to identify the Fe-clustering degree by following both magnetic susceptibility as well as magnetization values at $2 \mathrm{~K}$. Thanks to this, we demonstrated that TEA induces an increment in Fe-clustering. Electrochemical OER measurements show that both samples behave identically by using glassy carbon electrodes. Interestingly, when the samples are tested in the most commonly employed electrode, nickel foam, striking differences arise. The sample exhibiting a lower Fe-clustering behaves as a better electrocatalyst with a reduction of the overpotential values of more than $50 \mathrm{mV}$ to reach $100 \mathrm{~mA} \mathrm{~cm}^{-2}$, as a consequence of a favoured surface transformation of $\mathrm{MgFe}-\mathrm{LDH}$ s phases into more reactive oxyhydroxide NiFe-based phases during the electrochemical tests. Hence, this work alerts about the importance of the electrocatalyst-electrode collector interactions which can induce misinterpretations in the OER performance.
\end{abstract}

\section{Introduction}

In recent years, concerns related to global energy demand and its pollution consequences have led to the search for environmentally friendly solutions in the fields of energy storage and conversion. In this context, and in line with the European Green Deal policy, water splitting technologies represent the main strategy towards the transformation of sustainable resources into chemical energy; thus, hydrogen stands up as the fuel of the future allowing a promising transition to a clean and circular economy. ${ }^{1}$ The water splitting process is a thermodynamically uphill reaction $\left(\Delta G=286 \mathrm{~kJ} \mathrm{~mol}^{-1}\right.$ at environmental conditions: room temperature and atmospheric pressure) which requires the employment of specific electrocatalysts to be carried out efficiently. In addition, the oxygen evolution reaction (OER) is reckoned as the limiting step of the energy process, suffering slow kinetics $(>10000$ lower than the

Instituto de Ciencia Molecular (ICMol), Universitat de València, Catedrático José Beltrán 2, 46980 Paterna, Valencia, Spain. E-mail: gonzalo.abellan@uv.es

$\dagger$ Electronic supplementary information (ESI) available. See DOI: 10.1039/ d1dt03737d

$\$$ Both authors contribute equally to this work. hydrogen evolution reaction), and therefore requiring high overpotentials, which trigger the main energy losses. ${ }^{2}$ For this reason, currently much of the efforts of the scientific community are focused on the design and development of earth-abundant electrocatalysts for the OER; $;^{3-5}$ in particular, considering that nowadays precious metal oxides such as ruthenium oxide $\left(\mathrm{RuO}_{2}\right)$ or iridium oxide $\left(\mathrm{IrO}_{2}\right)$ are utilized as state-of-the-art electrocatalysts for the OER under alkaline conditions. ${ }^{6,7}$

In this front, iron is one of the most attractive earth-abundant electrocatalytic elements for water splitting technologies. Its huge abundance in the Earth's crust, low toxicity, and high efficiency for $\mathrm{O}_{2}$ activation distinguish it from other transition metals. Interestingly, many reports focused on Fe-based materials (metal oxides, layered hydroxides or MOFs, among others) have demonstrated a synergistic effect between $\mathrm{Fe}$ centres and other transition metal cations. ${ }^{8-12}$ In fact, the synergy with the nearest neighbour (3d cations) sites through the formation of O-bridges, induces an increment in the electrical conductivity of Fe-based catalysts favouring their performance. ${ }^{13}$

Among the Fe-based materials, layered double hydroxides (LDHs) represent a key family of catalyst for OER. These layered structures are composed of divalent $\left(\mathrm{M}^{\mathrm{II}}\right)$ and trivalent 
$\left(\mathrm{M}^{\mathrm{III}}\right)$ cations located in octahedral environments, where the two dimensional (2D) positively charged layers stack by the incorporation of the anion $\left(\mathrm{A}^{\mathrm{n}-}\right.$ inorganic, organic, macromolecules, etc.) and solvent molecules into the interlayer space. ${ }^{14-16}$ These highly tunable structures, defined by the formula $\mathrm{M}_{1-x}^{\mathrm{II}} \mathrm{M}_{x}^{\mathrm{III}}(\mathrm{OH})_{2} A_{n / x}{ }^{n-} \cdot m\left(\mathrm{H}_{2} \mathrm{O}\right)$, represent a perfect platform to design Fe-based materials with interesting properties for use in several fields such as anion exchange, water cleaning, magnetism, catalysis, energy storage, anticorrosion, drug delivery, among others. ${ }^{17-20}$

Currently, 2D NiFe-LDHs have attracted increasing attention due to their outstanding performance in OER in basic media. $^{21-23}$ In this sense, different approximations have been carried out to understand and enhance their electrocatalytic behaviour: exfoliation, ${ }^{24,25}$ doping with other metal cations, ${ }^{26,27}$ defect engineering (cations and/or oxygen vacancies) ${ }^{28}$ formation of hybrid materials, ${ }^{29}$ or increment of the interlayer space, ${ }^{30}$ to name few. Moreover, in situ techniques such as X-ray absorption (XAS), Raman, and Mössbauer spectroscopy have demonstrated that Fe cations act as catalytic centres. ${ }^{31}$ However, despite all these considerable efforts, there is a lack of information related to the specific role of the atomic distribution of $\mathrm{Fe}$ centres along the LDH sheets towards the OER activity. Cation clustering has been an important matter of study in LDHs for many years including both Aland Fe-based materials. ${ }^{32-34}$ Remarkably, as reported by Kawabata et al. for MgAlFe LDH samples, those exhibiting higher amounts of $\mathrm{Fe}-\mathrm{O}-\mathrm{Fe}$ moieties are catalytically more active in terms of the Baeyer-Villiger oxidation/reaction. ${ }^{35}$

Therefore, to shed light on the influence of Fe clustering on OER performance, we have selected as a model system MgFebased LDHs due to the non-electrocatalytic role of $\mathrm{Mg}$ as divalent cation. This will permit to evaluate exclusively the role of Fe centres; at the same time, the diamagnetic $\mathrm{Mg}$ cations will allow us to assess Fe distribution by using conventional magnetic characterization (i.e.: Fe-clustering versus Fe-isolated distribution). For that, we have optimized the hydrothermal synthesis of MgFe-based LDHs by employing TEA as a chelating agent (MgFe-TEA), previously introduced by us as an effective synthetic route for the synthesis of pure (spinel-free) hexagonal NiFe-based LDHs showing high crystallinity. ${ }^{36}$ Since the formation of Fe-TEA complexes prevents the precipitation of insoluble iron hydroxides, ${ }^{37}$ this approach could serve as a tool for controlling Fe-clustering. Indeed, the magnetic characterization supports our hypothesis. The sample obtained through the TEA approach depicts higher antiferromagnetic ordering and lower magnetization values $\left(M_{\mathrm{S}}\right)$ at $2 \mathrm{~K}$, suggesting a higher proportion of antiferromagnetic (AF) Fepairs, i.e.: higher Fe-clustering. However, in terms of water splitting reaction, both $\mathrm{MgFe}-\mathrm{LDH}$ samples exhibit the same OER performance when glassy carbon collector electrodes are used. Remarkably, the OER performance on nickel foam (the most widely used electrode collector) displays clear differences. The MgFe sample containing the lower Fe-clustering exhibits a better OER performance in comparison with the highly clustered one, which linearly increases with the current density: less than $50 \mathrm{mV}$ of overpotential to reach $100 \mathrm{~mA} \mathrm{~cm}{ }^{-2}$. These results suggest that the interaction between the electrocatalytic material and the electrode collector can drive changes in the nature of the pristine electrocatalyst modifying its inherent reactivity, i.e.: formation of highly reactive NiFe (oxo)hydroxides during the activation process and electrochemical tests in the case of Ni-foam electrode collectors. Hence, these results suggest that rational chemical improvements such as cationic doping, vacancy incorporation or defect engineering ${ }^{38-40}$ performed to boost the OER performance of LDHs should be measured employing inert electrode collectors in order to avoid misinterpretation.

\section{Results and discussion}

To address the role of Fe-clustering on OER performance, we decided to employ the $\mathrm{MgFe}=2: 1 \mathrm{LDH}$ phase as a model system. This choice is based on three main reasons: (i) the $\mathrm{Mg}: \mathrm{Fe}=2: 1$ ratio represents the highest possible value for a $\mathrm{LDH}$ structure, (ii) $\mathrm{Mg}$ (II) is a non-electrocatalytic cation that allows us to explore the role of the electrocatalytic Fe-centres, exclusively; in addition, (iii) diamagnetic $\mathrm{Mg}$ (II) permits to track Fe-clustering by conventional magnetic measurements (Scheme 1).

The MgFe-based LDHs were hydrothermally synthesized at $120{ }^{\circ} \mathrm{C}$ for $24 \mathrm{~h}$ by employing ammonia as the alkalinisation reagent. Due to the higher solubility of $\mathrm{Mg}$-based LDHs, the initial $\mathrm{pH}$ needs to be adjusted to 10.5 to ensure the complete precipitation of both cations. ${ }^{41,42}$ Specifically, triethanolamine (TEA) is added to the solution as a chelating agent (atrane route), where Fe-TEA complex formation could be used to modulate the Fe-clustering. The formation of Fe-TEA complexes can be easily evidenced by the change in the colour of the solution (Fig. 1C - inset) and confirmed by UV-vis spectroscopy (see Fig. S1†).

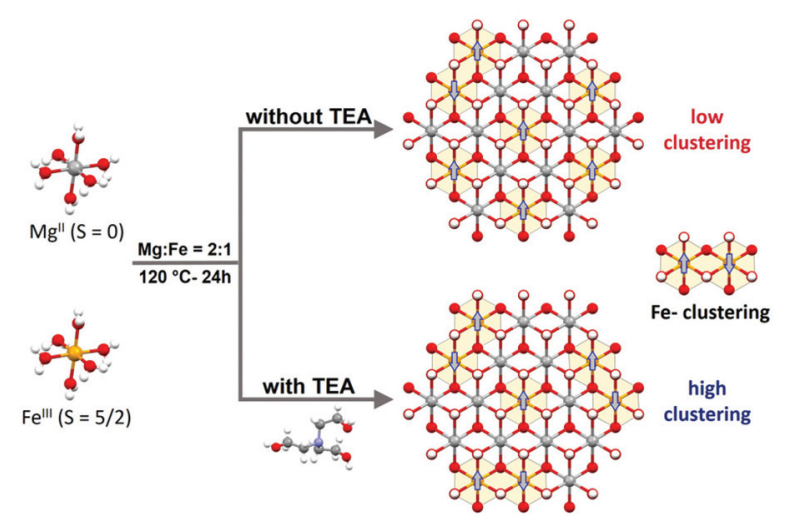

Scheme 1 MgFe-based LDHs (Mg: $\mathrm{Fe}=2: 1$ ratio) are synthesized hydrothermally with ammonia at $120^{\circ} \mathrm{C}$ for $24 \mathrm{~h}$. In the case of samples obtained through the TEA approach, a higher Fe-clustering degree is observed which triggers changes in the magnetic behaviour of the final MgFe-based LDHs, even at the same $\mathrm{Mg}: \mathrm{Fe}=2: 1$ ratio. 
A

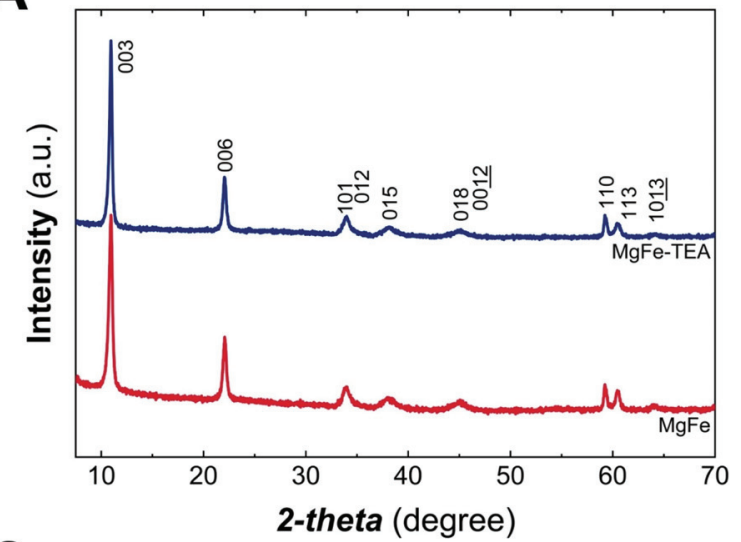

C

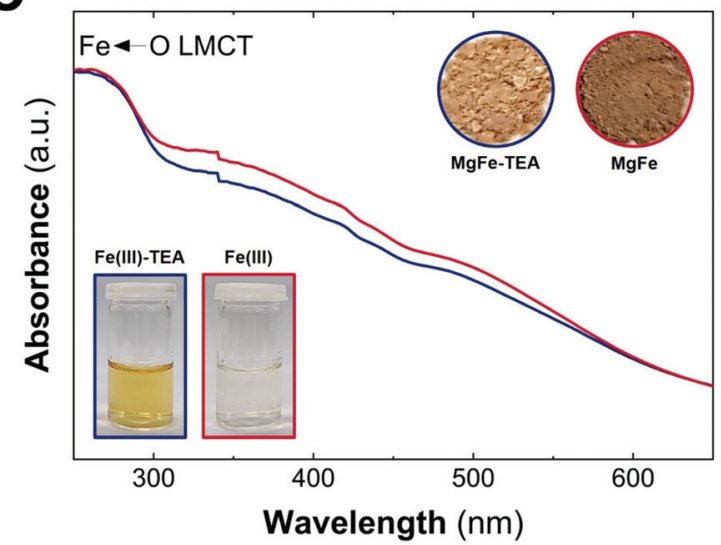

B

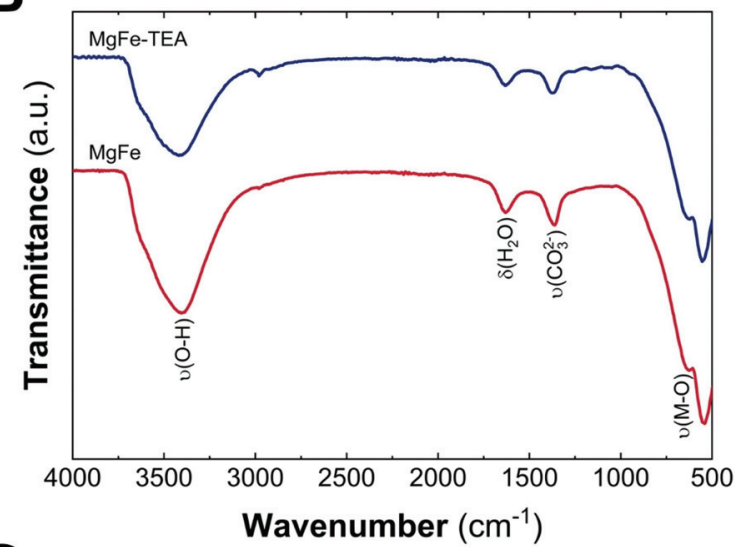

D

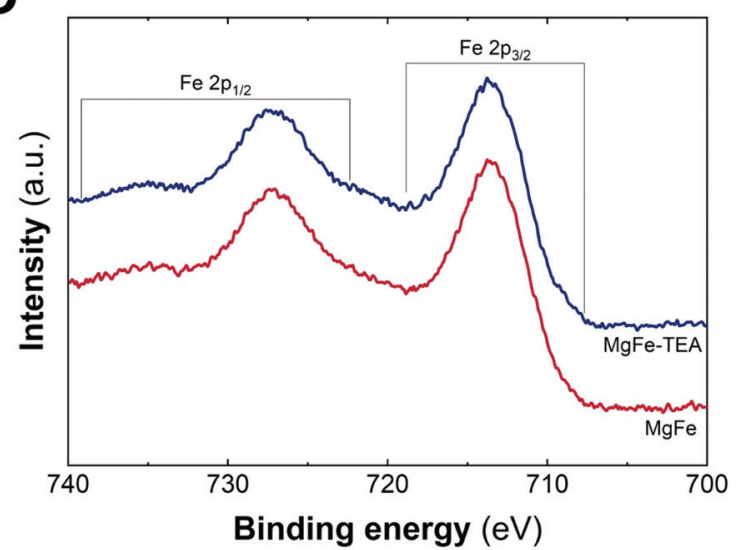

Fig. 1 Structural and physicochemical characterization of MgFe samples obtained with (blue) and without (red) TEA: PXRD patterns (A); ATR-FTIR and (B) UV-vis diffuse reflectance. (C) The insets depict the digital photographs of iron aqueous solution with and without TEA (Fe(III)-TEA and Fe(III), respectively) and the obtained solids, MgFe-TEA and MgFe; high resolution Fe 2p XPS spectra in the range of 740-700 eV (D).

Fig. 1A depicts the PXRD patterns of MgFe-based LDHs samples, where crystalline materials obtained in both cases, with and without TEA, are denoted as MgFe-TEA and MgFe, respectively. The two main peaks at low 2-theta values, $c a .11^{\circ}$ and $22^{\circ}$, ascribed to interlayer reflections, exhibit a basal space distance $\left(d_{\mathrm{BS}}\right)$ value of around $8 \AA$. On the other hand, the signal centred around 2-theta $=59.2^{\circ}$ is associated with the intralayer distance $\left(d_{110}\right)$. The calculated structural parameters and the crystallite size along both cell axes $\left(L_{00 l}\right.$ and $\left.L_{110}\right)$ evidence similar values, suggesting no marked changes in the aging process as a function of TEA concentration (see Table S1 $\dagger$ ). Furthermore, attenuated total reflectance Fouriertransform infrared spectroscopy (ATR-FTIR) confirms the partial incorporation of carbonate as interlayer anion, according to the signal around $1365 \mathrm{~cm}^{-1}$. Signals at $c a .3400$ and $1630 \mathrm{~cm}^{-1}$ are assigned to water molecules, while those ones below $750 \mathrm{~cm}^{-1}$ correspond to $\mathrm{M}-\mathrm{O}$ vibrations, as shown in Fig. 1B. In addition, UV-vis diffuse reflectance spectroscopy (UV-vis) gives an initial clue of the possibility of having different $\mathrm{Fe}$-arrangements, considering that the $\mathrm{MgFe}$ solid sample is slightly darker than the MgFe-TEA one (Fig. 1C inset). The absorption band below $300 \mathrm{~nm}$ could be ascribed to the ligand-to-metal charge transfer (from the hydroxyl ligands to $\mathrm{Fe}(\mathrm{III})$ cations), while the shoulders centred in the range $300-400 \mathrm{~nm}$ and around $500 \mathrm{~nm}$ might be associated with oligomeric and aggregated large-sized iron clusters, respectively. ${ }^{43-45}$ Sample MgFe depicts slightly larger shoulders in both regions, that could be interpreted as the first evidence of the role of TEA on the Fe-clustering modulation. Moreover, X-ray photoelectron (XPS) spectroscopy was performed to evaluate the chemical composition and oxidation state of iron. Fig. 1D depicts the XPS spectra where the main peaks centred at $713.7\left(2 \mathrm{p}_{3 / 2}\right)$ and $727.3 \mathrm{eV}\left(2 \mathrm{p}_{1 / 2}\right)$ confirm the presence of Fe (III), as expected. ${ }^{46}$ In addition, the XPS spectra of magnesium and chloride display slight differences which could also be related to Fe-clustering (see Fig. S2 and S3†). In both samples, the presence of chloride was observed in a $\mathrm{Fe}: \mathrm{Cl}$ ratio of 0.7. Finally, and in combination with EDS and ICP-MS measurements, $\mathrm{Mg}: \mathrm{Fe}$ and $\mathrm{Cl}$ : $\mathrm{Fe}$ have been estimated to be $2.0 \pm 0.1$ and $0.6 \pm 0.1$ for both samples (see Table S1†).

As a complement experiment to discard the presence of TEA molecules on an MgFe-TEA sample, which may affect either the magnetic properties and could alter the electrochemistry characterization, ${ }^{47}$ we have performed thermo- 
gravimetric analysis coupled with gas chromatography and mass spectrometry (TG-GC-MS) under an inert atmosphere of helium. This technique arises as a powerful way to analyse the presence of ligands, impurities, and track the thermal evolution of LDH samples. ${ }^{48,49}$ Fig. 2A shows the thermogravimetric analysis of both samples. The indistinguishable decomposition profiles suggest the lack of coordinated TEA molecules in MgFe-TEA samples. In addition, the elugrams for the injections at 270 and $300{ }^{\circ} \mathrm{C}$ (figures $\mathrm{B}$ and $\mathrm{C}$, respectively) confirm the presence of the $\mathrm{CO}_{2}$ and $\mathrm{H}_{2} \mathrm{O}$ molecules during the LDH phase decomposition, exclusively. Therefore, we can satisfactorily conclude the obtaining of free-TEA MgFe-LDHs samples.

Fig. 3 depicts the electron microscopy characterization performed with TEM. The presence of platelets displaying rounded edges with a diameter of around $100-160 \mathrm{~nm}$ is observed for the entire MgFe-LDH family, without any evidence of spinel impurities. In addition, AFM measurements confirm the anisotropy of the samples with thicknesses lower than $25 \mathrm{~nm}$ for both samples (aspect ratios 5-10) highlighting the inherent 2D growth of layered hydroxides. ${ }^{50}$

After confirming the synthesis of crystalline 2D platelets of $\mathrm{MgFe}$ LDHs, we decided to evaluate the role played by TEA on Fe-clustering by performing conventional magnetic characterization. Specifically, the magnetic behaviour of the $\mathrm{LDH}$ phases is controlled by two main contributions: on the one hand, the intralayer (in-plane) magnetic superexchange between magnetic centres through the $\mathrm{OH}$ bridges, representing the main factor; on the other hand, the less intense interlayer (out-of-plane) dipolar interactions. ${ }^{15}$ Considering the dia-
A

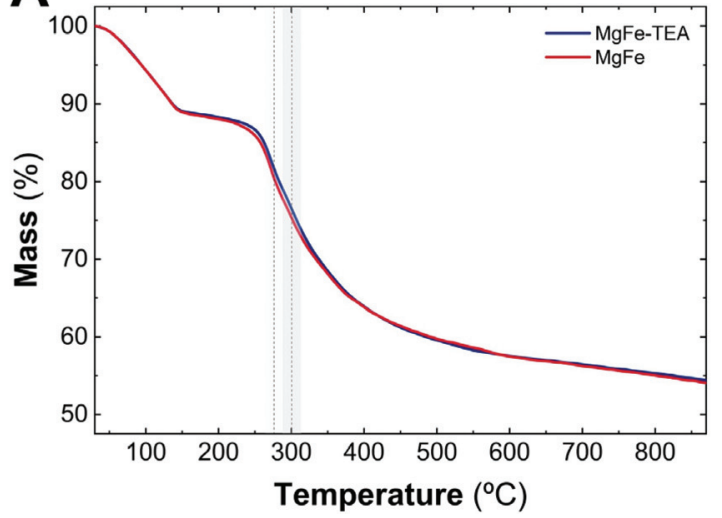

B

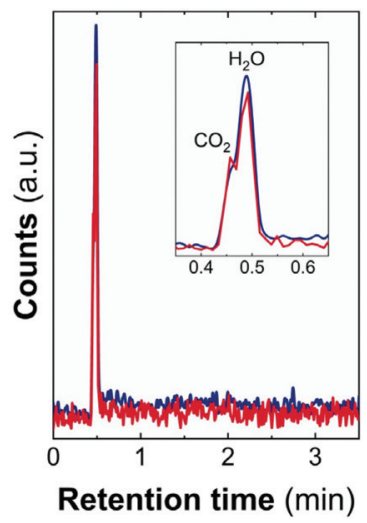

C

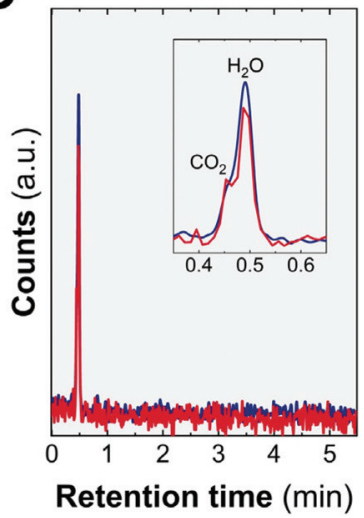

Fig. 2 TG-GC-MS characterization. TG patterns of MgFe-TEA (blue) and MgFe (red) recorded at $10{ }^{\circ} \mathrm{C} \mathrm{min}{ }^{-1}$ under an inert atmosphere of helium (A). During the decomposition process, the evolved gaseous fragments are injected in a preheated GC column at $40^{\circ} \mathrm{C}$. After chromatographic separation, the molecules were identified by MS. Elugrams from the injection at 270 (B) and $300{ }^{\circ} \mathrm{C}$ (C) only allow us to identify $\mathrm{CO}_{2}$ and $\mathrm{H}_{2} \mathrm{O}$ molecules during the decomposition process.
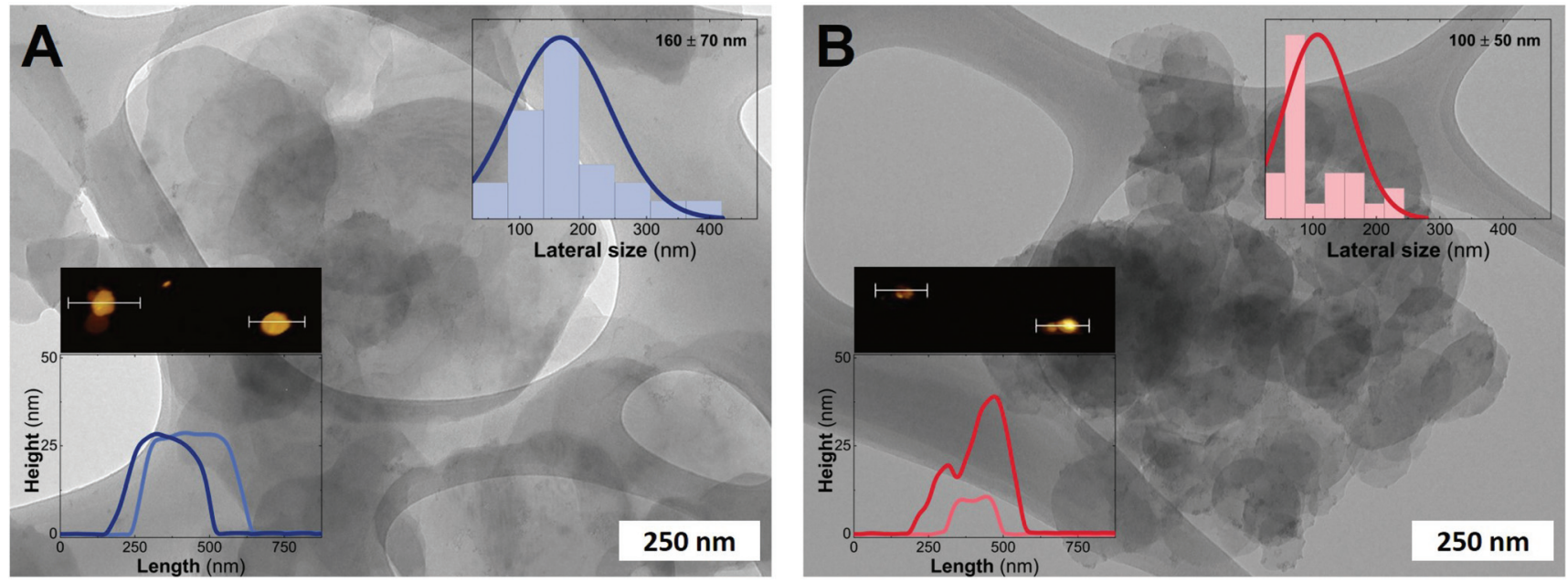

Fig. 3 TEM images of MgFe-based LDHs obtained hydrothermally at $120^{\circ} \mathrm{C}$ and a $24 \mathrm{~h}$ aging process with and without TEA as the capping agent; $\mathrm{MgFe}-\mathrm{TEA}(\mathrm{A})$ and MgFe (B), respectively. Insets: Histograms obtained after measuring at least 50 particles. AFM images reveal an estimated thickness lower than $35 \mathrm{~nm}$ for both samples. 
A

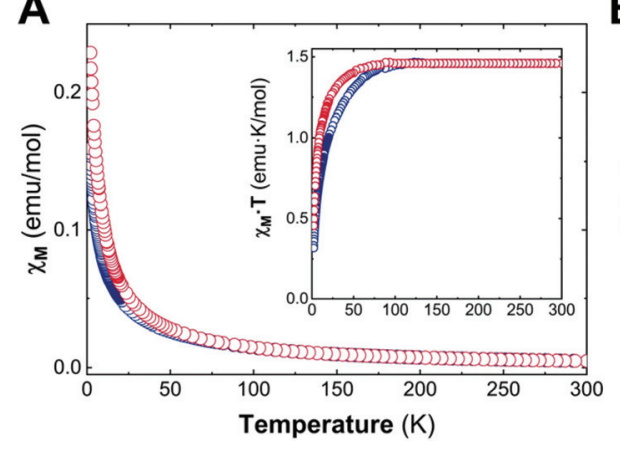

B

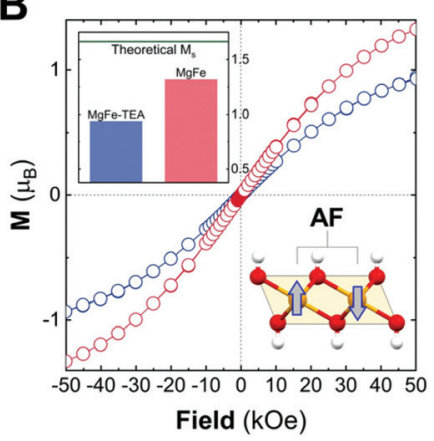

C
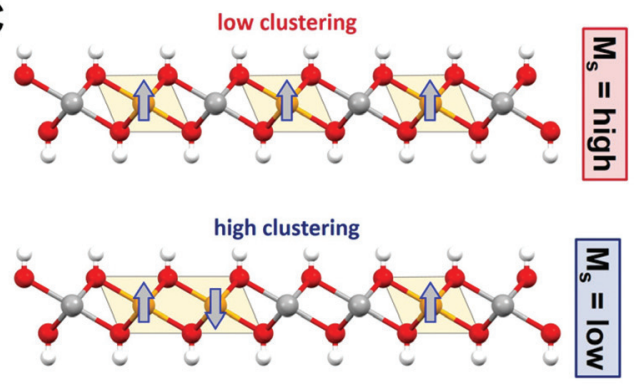

Fig. 4 Magnetic characterization of the MgFe samples with (blue) and without (red) TEA. Magnetic susceptibility as a function of temperature $\left(X_{M}\right.$ vs. $T$ ) with an external applied field of $1000 \mathrm{Oe}$; the inset represents $\left(X_{\mathrm{M}} \cdot T\right.$ vs. $\left.T\right)(\mathrm{A})$. Isothermal magnetization recorded at $2 \mathrm{~K}$; the inset depicts the experimental $M_{s}$ values in comparison to the theoretical $M_{s}$ one (B). Schematic idealized representation of the effect of Fe-clustering over the $M_{s}$ values (C).

magnetic behaviour of $\mathrm{Mg}$ cations $(S=0)$, the magnetic response of the MgFe-based LDH samples is exclusively governed by $\mathrm{Fe}(\mathrm{III})$ cations $(S=5 / 2)$ and their distribution; thus, in the case of neighbouring iron cations, an antiferromagnetic (AF) coupling is expected, i.e.: $\mathrm{Fe}-\mathrm{OH}-\mathrm{Fe}$ moieties. Hence, conventional magnetic characterization allows us to evaluate this process for the whole sample. ${ }^{33,51,52}$

To begin with, we analysed the temperature-dependent magnetic susceptibility measurements $\left(\chi_{\mathrm{M}} v s . T\right.$ plot $)$ in order to exclude the presence of electroactive iron oxide impurities. ${ }^{53}$ Fig. $4 \mathrm{~A}$ depicts the temperature-independent component in $\chi_{\mathrm{M}}$ vs. $T$ at high temperature for both cases, thus confirming the purity of the MgFe-based LDH samples. It is worth mentioning that the Fe-oxide spinel phases are hard to identify with conventional techniques (PXRD, TEM, etc.). Therefore, magnetic characterization emerges as a very useful technique for $\mathrm{Fe}-$ based LDHs. ${ }^{53}$ In addition, the MgFe-TEA sample depicts lower values in the $\chi_{\mathrm{M}} v s . T$ plot, in comparison with the MgFe one, suggesting more AF behaviour. In the case of the $\chi_{\mathrm{M}} \cdot T v s$. $T$ plot (see Fig. 4A-inset), the signal for the MgFe-TEA sample decays at higher temperatures ( $c a .80$ vs. $50 \mathrm{~K}$ ) suggesting stronger AF couplings, which can be understood as an increment in the $\mathrm{Fe}-\mathrm{OH}-\mathrm{Fe} \mathrm{AF}$ interactions, i.e.: a higher Fe-clustering. In accordance with this, applying the Curie-Weiss law above $150 \mathrm{~K}$ (see Fig. S4†), the Weiss constant $(\Theta)$ presents a more negative value for the MgFe-TEA sample, which reflects higher AF contribution (see Table S2 $\dagger$ ).

To finally confirm the differences in the degree of Fe-clustering in $\mathrm{MgFe}$-based samples, isothermal magnetization at $2 \mathrm{~K}$ was recorded as a function of the magnetic field, $M_{\mathrm{s}}$ (Fig. 4B). For MgFe-based LDH without Fe-clustering, this value can be estimated at $c a .1 .67 \mu_{\mathrm{B}}$. Thus, any decrease from this value should be ascribed to Fe-clustering, as the AF Fe$\mathrm{OH}-\mathrm{Fe}$ pairs do not contribute to the magnetic moment at this temperature $(2 \mathrm{~K}){ }^{54}$ The experimental $M_{\mathrm{S}}$ values for the $\mathrm{MgFe}$ and MgFe-TEA samples are 1.32 and $0.94 \mu_{\mathrm{B}}$, respectively, confirming the presence of Fe-clustering. By comparing with the theoretical $M_{\mathrm{S}}$ value, we can estimate a deviation of $21 \%$ and $44 \%$ for $\mathrm{MgFe}$ and MgFe-TEA samples, respectively. In brief, the tendency of magnetic parameters evidence a higher degree of Fe-clustering in the MgFe-TEA sample compared to the $\mathrm{MgFe}$ one (Fig. 4C).

Upon confirming the role of TEA in Fe-clustering, we decided to evaluate whether different degrees of clustering have a role in the electrocatalytic behaviour, specifically on the oxygen evolution reaction (OER) performance in basic media by employing glassy carbon collectors (GC). In this case, the electrocatalytic activity can be directly studied from linear sweep voltammetry (LSV) recorded at $5 \mathrm{mV} \mathrm{s}^{-1}$ up to $3.2 \mathrm{~V} v s$. RHE. The electrocatalytic behaviour of both the MgFe-LDH samples in comparison with bare GC electrodes is depicted in Fig. 5. As it is clearly observed, Fe-based LDHs display a significant catalytic behaviour, highlighting the role of Fe as the catalytic center. ${ }^{55-58}$ However, judging from the LSVs, the OER performance is not affected by the degree of clustering in the MgFe LDH samples.

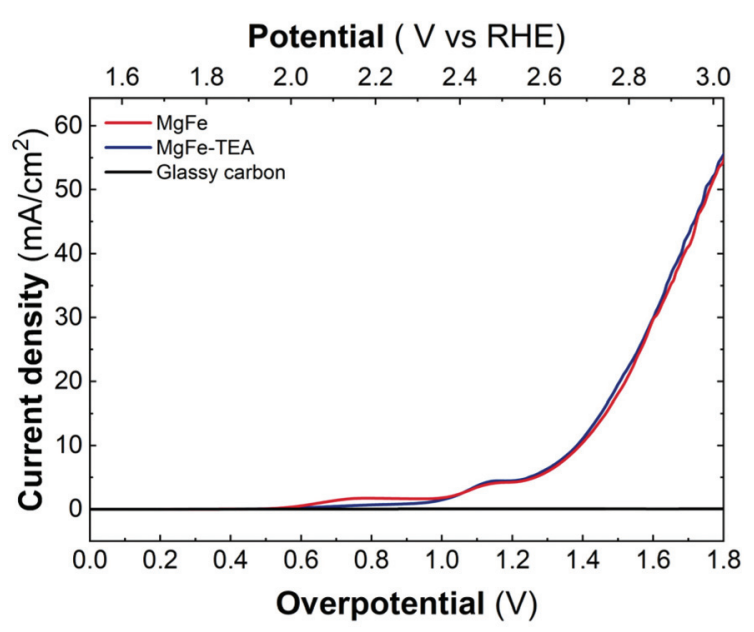

Fig. 5 Linear sweep voltammetry (LSV) recorded at $5 \mathrm{mV} \mathrm{s}^{-1}$ in $1 \mathrm{M}$ $\mathrm{KOH}$ solution by employing glassy carbon collectors for samples obtained with and without TEA, MgFe-TEA (blue) and MgFe (red), in comparison with the bare collector (black). 


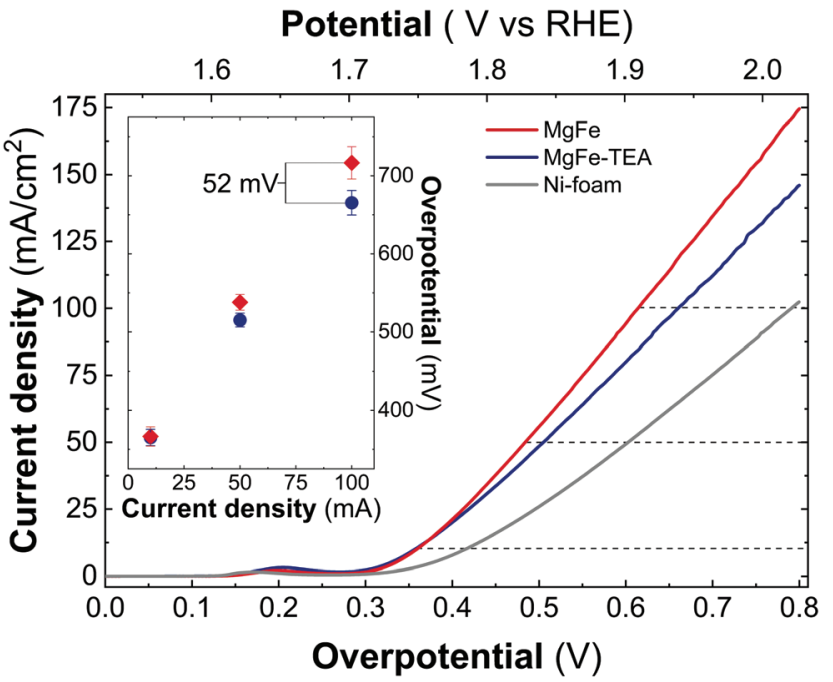

Fig. 6 Linear sweep voltammetry (LSV) recorded at $5 \mathrm{mV} \mathrm{s}^{-1}$ in $1 \mathrm{M}$ $\mathrm{KOH}$ solution for samples obtained with and without TEA, MgFe-TEA (blue) and $\mathrm{MgFe}$ (red), in comparison with an $\mathrm{Ni}$-foam collector (gray). The inset shows the extracted overpotential at 10,50, and $100 \mathrm{~mA} \mathrm{~cm}{ }^{-2}$ for both samples, MgFe-TEA (blue) and MgFe (red).

In addition, both samples were also tested on Ni-foam collectors-the most employed OER electrode-by measuring LSV at $5 \mathrm{mV} \mathrm{s}^{-1}$ up to $2.0 \mathrm{~V}$ vs. RHE (Fig. 6). As expected, the electrocatalytic behaviour of both MgFe LDHs samples is much better than the ones recorded on GC electrodes showing lower OP values, mainly due to the inherent conductivity of Ni-foam. However, striking differences between both samples arise: In contrast to GC electrodes, the MgFe sample exhibiting the lower Feclustering degree considerably outperformed the MgFe-TEA one. To quantify these differences, the overpotential at different current densities (Fig. 6 - inset) and the differences in the OP for both samples $\left(\mathrm{OP}_{\mathrm{MgFe}}-\mathrm{OP}_{\mathrm{MgFe}-\mathrm{TEA}}\right)$ as a function of the current density were calculated (Fig. S5†). Remarkably, a difference of $c a$. $52 \mathrm{mV}$ at $100 \mathrm{~mA} \mathrm{~cm}{ }^{-2}$ can be measured. It is worth to mention that the OP values have been extracted from at least three LSV measurements. Furthermore, in order to discard the possibility of assigning these changes to different electrolyte accessibilities as a consequence of structural modifications during the surface reconstruction of the catalysts, we measured the electrochemical surface area (ECSA) (see Fig. S6† for further details). Overall, the observed tendencies indicate that the MgFe sample behaves as a better electrocatalyst when Ni-foam electrodes are employed.

Taking into account the identical OER performance of GC electrodes (Fig. 5), these results alert about some interaction between the electrocatalytic LDH materials and the Ni-foam electrode surface. To shed light on this, cyclic-voltammetry (CV) at $5 \mathrm{mV} \mathrm{s}^{-1}$ for bare Ni-foam, MgFe@Ni-foam, MgFeTEA@Ni-foam after an activation process of 20 cycles was conducted (see Fig. S7†). In all of them, it is possible to observe the redox couple $\mathrm{Ni}(\mathrm{II}) / \mathrm{Ni}$ (III) with a peak in the range of 1.2-1.5 V vs. RHE (Fig. 7). It is worth noting that this redox signal is attributed to the presence of the surface oxidation of the collector, Ni(II)-based (oxo)hydroxides, as reported for com-

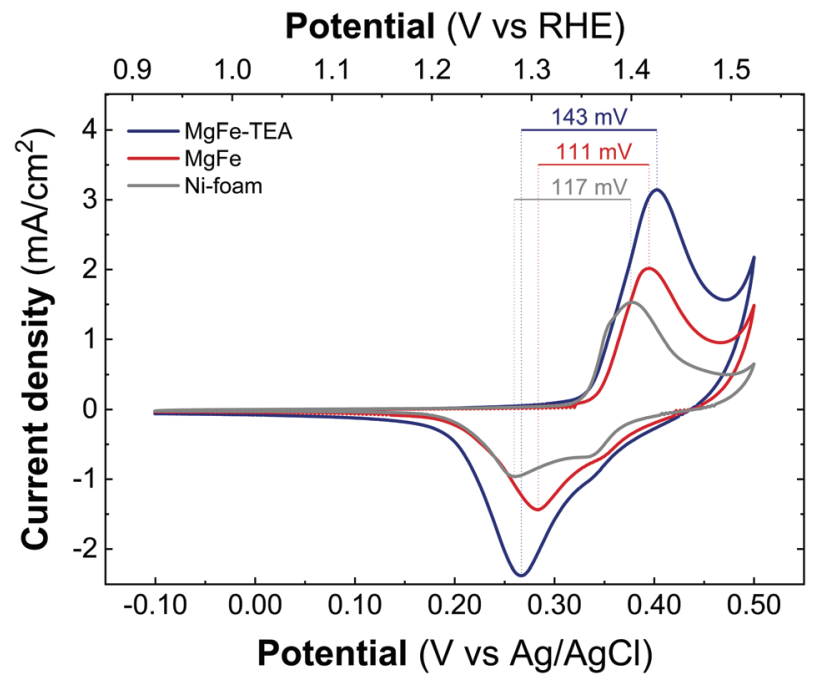

Fig. 7 Cyclic voltammetry recorded at $5 \mathrm{mV} \mathrm{s}^{-1}$ between $-0.1 \mathrm{~V}$ and $0.4 \mathrm{~V}$ versus $\mathrm{Ag} / \mathrm{AgCl}$ for the samples $\mathrm{MgFe}-\mathrm{TEA}$ (blue) and $\mathrm{MgFe}$ (red) and $\mathrm{Ni}$-foam (gray) after 20 cycles of the activation process.

mercially available Ni-foams. ${ }^{59}$ However, the CV of the electrodes containing the MgFe-LDH material shows a clear shift to a higher oxidation potential $(>25 \mathrm{mV})$, which is attributed to the incorporation of Fe cations on the Ni-foam. ${ }^{60}$ By analysing the difference between the maximum oxidation and reduction peaks, we can confirm that the MgFe sample behaves as the most reversible and conductive electrode. Therefore, this MgFe-LDH material exhibiting the lower Fe-clustering might work as a better OER catalyst. Indeed, these changes in the OER performance as a function of the electrode collector can be understood as the transformation of MgFe-LDHs into NiFeoxyhydroxide phases due to the higher stability of Ni-based LDHs in comparison with the Mg-based ones, as demonstrated by solubility constants. ${ }^{41,61,62}$ In addition, ex situ XPS measurements were recorded over the Ni-foam electrodes after OER activity (Fig. 8). While the Fe $2 \mathrm{p}_{3 / 2}$ peaks centred at $713.7 \mathrm{eV}$

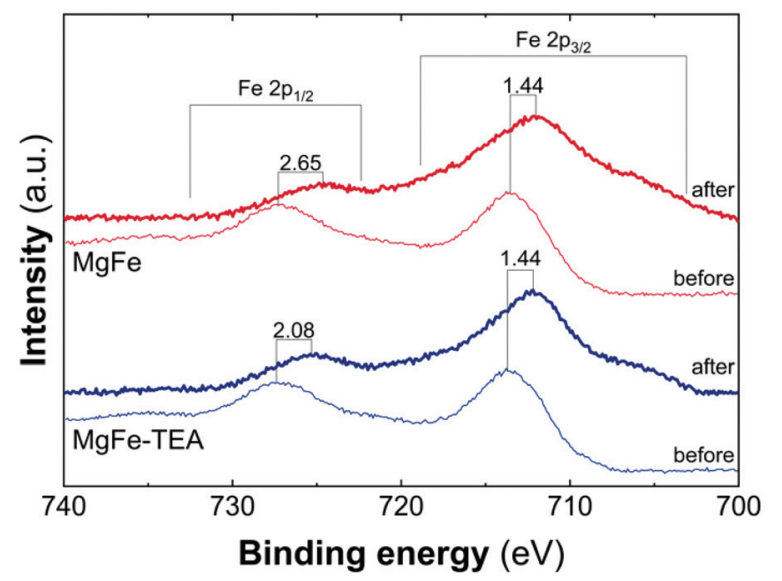

Fig. 8 High resolution Fe 2p XPS spectra in the range of $740-700 \mathrm{eV}$ for samples MgFe-TEA (blue) and MgFe (red) deposited on Ni-foam before and after the OER catalyst. 
shift by $1.44 \mathrm{eV}$ to lower binding energy values for both samples, the Fe $2 \mathrm{p}_{1 / 2}$ peaks positioned at $727.3 \mathrm{eV}$ are shifted 2.08 and $2.65 \mathrm{eV}$ for the MgFe-TEA and MgFe samples, respectively. In the case of the MgFe sample containing the lower Feclustering, this pronounced shift is associated with highly reactive Fe-sites. ${ }^{63}$

In summary, while the MgFe LDH samples containing different Fe-clustering behave identically in terms of OER performance on glassy carbon electrode collectors, the samples with lower Fe-clustering exhibit better OP values on Ni-foam collectors, with the $\mathrm{OP}_{\mathrm{MgFe}}-\mathrm{OP}_{\mathrm{MgFe}-\mathrm{TEA}}$ differences exceeding $50 \mathrm{mV}$ at $100 \mathrm{~mA} \mathrm{~cm}^{-2}$. These marked changes are attributed to the surface reconstruction effects along with the electrochemical tests, which are more pronounced for the most ordered catalysts (lower cation clustering) leading to highly reactive Fe-sites.

\section{Experimental}

\section{Chemicals}

Magnesium chloride hexahydrate $\left(\mathrm{MgCl}_{2} \cdot 6 \mathrm{H}_{2} \mathrm{O}\right)$, iron chloride hexahydrate $\left(\mathrm{FeCl}_{3} \cdot 6 \mathrm{H}_{2} \mathrm{O}\right)$, ammonium hydroxide solution, triethanolamine (TEA, $\mathrm{C}_{6} \mathrm{H}_{15} \mathrm{NO}_{3}$ ), acetylene black, and polytetrafluoroethylene (PTFE) were purchased from SigmaAldrich. Potassium hydroxide (KOH, 99.99\%) and ethanol absolute (EtOH) were purchased from Panreac. All chemicals were used as received. Milli-Q water was obtained from Millipore Milli-Q equipment.

\section{Synthesis of MgFe-LDHs}

$\mathrm{MgFe}-\mathrm{LDH}$ was synthesized with an $\mathrm{Mg}:$ Fe ratio of $2: 1$ using a hydrothermal method. In a typical procedure, the chloride salts of the metals were dissolved in $90 \mathrm{~mL}$ of a $1: 1(\mathrm{v} / \mathrm{v})$ ethanol/water Milli-Q mixture without or with TEA (in a TEA : Fe ratio of 23 according to the previous report) ${ }^{30,64}$ reaching in both cases a total concentration of metal cations of $20 \mathrm{mM}$. Afterward, under an argon atmosphere, ammonium hydroxide solution was added until the $\mathrm{pH}$ was set at 10.5. The resulting solution was mixed thoroughly and transferred to a Teflon-lined stainless steel autoclave. The autoclave was placed in a preheated oven at $120^{\circ} \mathrm{C}$ for $24 \mathrm{~h}$. Finally, it was cooled to room temperature, and the final powder was filtered and washed with $\mathrm{H}_{2} \mathrm{O}$ and EtOH several times and dried for $24 \mathrm{~h}$ under vacuum. The samples were labelled as MgFe-TEA (synthesis with TEA) and MgFe (synthesis without TEA).

\section{Chemical and structural characterization}

Powder X-ray powder diffraction (PXRD) patterns were obtained by employing a PANalytical Empyrean X-ray platform with a capillary platform and copper radiation $(\mathrm{Cu} \mathrm{K \alpha}=1.541$ $78 \AA$ ). Measurements were carried out in triplicate in the 2 -theta range $2-70^{\circ}$ by employing a step size of $0.02^{\circ}$ per step with an integration time of $1 \mathrm{~s}$. The attenuated total reflectance-Fourier transform infrared spectroscopy (ATR-FTIR) spectra were recorded using a Bruker alpha II FTIR spectro- meter in the $4000-400 \mathrm{~cm}^{-1}$ range. The UV-vis absorption spectra of the solid samples were recorded in the reflectance mode by using a Jasco V-670 spectrometer. X-ray photoelectron spectroscopy (XPS) spectra were recorded using a Thermo Scientific $^{\mathrm{TM}}$ K-Alpha X-ray Photoelectron Spectrometer. Al K $\alpha$ $\mathrm{X}$-ray radiation was employed as the X-ray source. For all the elements, more than 100 spectra were recorded by employing a step of $0.1 \mathrm{eV}$ with a focused spot higher than $400 \mu \mathrm{m}$. XPS data were analysed with the Thermo Avantage v5.9912 software.

Inductively coupled-plasma mass spectrometry (ICP-MS). The ICP-MS analysis was conducted at the Universidad de Valencia (Sección de Espectrometría Atómica y Molecular). Samples were digested in an acid medium.

Magnetic data were collected over the bulk material using a Quantum Design superconducting quantum interference device (SQUID) MPMS-XL-5. The magnetic susceptibility of the samples was corrected considering the diamagnetic contributions of their atomic constituents as deduced from Pascal's constant tables and the sample holder. In addition, a small TIP term $\left(\chi_{\mathrm{M}}=C /(T-\theta)+\chi_{\text {TIP }}\right)$ was applied as previously reported for the hydroxide samples. ${ }^{65}$ The DC data were recorded under an externally applied field of 1000 Oe in the 2-300 $\mathrm{K}$ temperature range. All magnetic measurements were carried out in eicosane, as this diamagnetic material allows for better immobilization of these small anisotropic crystals, precluding any artefact in the magnetic measurements.

Thermogravimetric analysis: TGA coupled to gas-chromatography (GC) and mass spectrometry (MS). Thermogravimetric analysis was carried out using a Netzsch TG 209 F1 Libra instrument. Mass loss and time-dependent temperature profiles in the range of 30 and $900{ }^{\circ} \mathrm{C}\left(10{ }^{\circ} \mathrm{C} \mathrm{min}^{-1}\right.$ heating rate $)$ were recorded under a constant flow of $\mathrm{He}\left(20 \mathrm{~mL} \mathrm{~min}^{-1}\right)$. The evolved gases detached from the respective samples in combination with the He carrier gas are transferred into a GC system through a preheated collector, transfer line, and a Netzsch VAB300 loop injector at a constant temperature of $300{ }^{\circ} \mathrm{C}$. The gas-chromatographic separation was achieved by an Agilent 8890 GC system equipped with a polysiloxane-coated Elite-5MS capillary column: $30 \mathrm{~m}$ length, $0.25 \mathrm{~mm}$ diameter, and $0.25 \mu \mathrm{m}$ film thickness. The GC injection fraction of $150 \mu \mathrm{L}$ was collected at different temperatures according to the steps observed in the TG profile for each sample. Two different conditions were evaluated. In the first case, the column was set at $40{ }^{\circ} \mathrm{C}$ in order to enhance the separation of the smallest molecules. In this case, after 30 minutes from the last injection, the temperature of the column was increased to desorb any retained molecule with a $20{ }^{\circ} \mathrm{C} \mathrm{min}^{-1}$ gradient and finally an isothermal step of $15 \mathrm{~min}$ at $280{ }^{\circ} \mathrm{C}$. In the second one, the column was set at $250{ }^{\circ} \mathrm{C}$ to characterize the largest molecules. In all the cases, MS measurements were performed using an Agilent 5977B GC/MSD. The obtained data were processed using the Agilent MassHunter Qualitative Analysis 10.0 Software and the bibliographic searches were performed with NIST MS Search 2.3. 


\section{Electrode preparation}

For electrochemical measurements using glassy carbon, an initial suspension was prepared by adding $25 \mu \mathrm{L}$ of $5 \%$ Nafion solution to $5 \mathrm{mg}$ of $\mathrm{LDH}$ powder and $2.5 \mathrm{mg}$ of graphitized carbon and then dispersed in $1.25 \mathrm{~mL}$ of $1: 1(\mathrm{v} / \mathrm{v}) \mathrm{EtOH} / \mathrm{H}_{2} \mathrm{O}$ and sonicated for $20 \mathrm{~min}$. Then, $5 \mu \mathrm{L}$ of this dispersion was dropcasted onto a previously polished (sequentially with 1.0, 0.3 , and $0.05 \mu \mathrm{m}$ alumina powder) $3 \mathrm{~mm}$ diameter RDE and dried at room temperature for $30 \mathrm{~min}$.

For the electrochemical measurements using Ni-foam, firstly a mixture of the LDHs, acetylene black and PTFE in ethanol in a mass ratio of $80: 10: 10$ was prepared and deposited on a nickel foam electrode. The as-prepared electrode was let dry for $2 \mathrm{~h}$ at $80^{\circ} \mathrm{C}$. Each working electrode contained around $0.4 \mathrm{mg}$ of the $\mathrm{LDH}$ sample and a square-like shape with edges of $1 \mathrm{~cm}$. The geometrical area of electrodes was determined as $1 \mathrm{~cm}^{2} \times 1 \mathrm{~cm}^{2}$ and thus electrode mass loading achieved was $0.4 \mathrm{mg} \mathrm{cm}^{-2}$.

\section{Electrochemical characterization}

A typical three-electrode cell equipped with a steel sheet as the counter electrode and a Metrohm $\mathrm{Ag} / \mathrm{AgCl}(3 \mathrm{M} \mathrm{KCl})$ as the reference electrode was used for the electrochemical characterization of the nanocomposite material trapped by the working electrodes, while an aqueous solution of $1 \mathrm{M} \mathrm{KOH} \mathrm{(99.99 \% )}$ was employed as the electrolyte. The glassy carbon measurements were performed with an Autolab rotating disc electrode (RDE) and analysed with an Autolab PGSTAT 128N potentiostat/galvanostat, while Ni-foam characterization was performed using a Gamry Interface $1000 \mathrm{E}$ potentiostat/galvanostat controlled by Gamry's Global Software. All the electrochemical experiments were performed at room temperature. Prior to OER experiments, an activation process of the prepared electrode (consisting of 20 voltammetric cycles between $-0.1 \mathrm{~V}$ and $0.5 \mathrm{~V}$ versus $\mathrm{Ag} / \mathrm{AgCl}$ at $100 \mathrm{mV} \mathrm{s}^{-1}$ ) was performed. Cyclic voltammetry curves (CVs) were obtained in the range of -0.1 to $0.5 \mathrm{~V}$ versus $\mathrm{Ag} / \mathrm{AgCl}$ at $5 \mathrm{mV} \mathrm{s}^{-1}$ to evaluate the redox behaviour of the materials. Linear sweep voltammetry (LSV) measurements were performed at $5 \mathrm{mV} \mathrm{s}^{-1}$ in a previously $\mathrm{N}_{2}$ purged $1 \mathrm{M} \mathrm{KOH}$ aqueous solution. All electrochemical experiments were done without $i \mathrm{R}$ correction, to make a fair comparison of the intrinsic electrocatalytic behaviour of each sample instead of searching for the best performance of the electrode.

Electrochemical surface area (ECSA) was acquired by measuring the current associated with the double-layer capacitance from the scan rate dependence of CVs. ECSA was measured on the working electrode after LSV measurements. The potential range used for the CVs was -0.1-0.1 V versus $\mathrm{Ag}$ / $\mathrm{AgCl}(3 \mathrm{M} \mathrm{KCl})$. The scan rates were 10, 20, 50, and $100 \mathrm{mV}$ $\mathrm{s}^{-1}$. The double-layer capacitance was calculated by plotting the $\left(j_{\mathrm{a}}-j_{\mathrm{c}}\right) / 2$ (anodic versus cathodic currents) at $0 \mathrm{~V}$ versus $\mathrm{Ag} /$ $\mathrm{AgCl}(3 \mathrm{M} \mathrm{KCl})$ against the scan rate. ECSA measurements were obtained using an Autolab PGSTAT 128N potentiostat/ galvanostat.

\section{Conclusions}

In this work, we have reported the modulation of the degree of Fe-clustering in 2D MgFe-based LDHs by employing TEA during hydrothermal synthesis. The diamagnetic behaviour of $\mathrm{Mg}$ (II) as a divalent cation allows having a platform to follow Fe-clustering by magnetic characterization. At the same time, the non-catalytic activity of $\mathrm{Mg}$ (II) for OER allows us to study the possible influence of Fe-clustering in OER performance. In this line, we observed that the Fe-TEA complex formation drives a higher degree of Fe-clustering in MgFe-LDHs, as demonstrated by the magnetic susceptibility and spontaneous magnetization measurements. Concerning OER performance, both samples are indistinguishable when measured using inert glassy carbon electrodes. Surprisingly, upon using nickel foam collectors, the MgFe sample containing the lower Fe-clustering degree exhibits a reduction in the overpotential values of more than $50 \mathrm{mV}$ to reach $100 \mathrm{~mA} \mathrm{~cm}{ }^{-2}$. These results, can be understood as the surface transformation of the MgFe-LDH phases into more reactive oxyhydroxide NiFe-based phases during the electrochemical tests. This work highlights the importance of the hidden electrocatalyst-electrode collector interactions during OER performance. An aspect that should be analyzed with care as it can lead to erroneous interpretations in the behavior of new electrocatalysts. In this sense, the use of inert electrode collectors in combination with nickel foams is recommended in order to reliably design new electrocatalytic materials based on LDHs.

\section{Conflicts of interest}

There are no conflicts to declare.

\section{Acknowledgements}

This work was supported by the European Research Council (ERC Starting Grant No. 2D-PnictoChem 804110 to G. A. and ERC Advanced Grant Mol-2D 788222 to E. C.), the Spanish MICINN (PID2019-111742GA-I00 to G. A., Unit of Excellence "Maria de Maeztu" CEX2019-000919-M, PDC2021-121106-I00 and project PID2020-117152RB-I00 co-financed by FEDER) and the Generalitat Valenciana (CIDEGENT/2018/001 to G. A., Prometeo/2021/022, and iDiFEDER/2018/061 co-financed by FEDER). A. S.-D thanks the Universidad de Valencia, for an 'Atracción del talento' predoctoral grant. The authors thank Ana Alemany-Domenech and Christian Olivares-Martínez for their assistance with the experimental work, Dr G. Agustí and Dr J. M. Martínez for the magnetic measurements and Dr M. D. Jordán-Martín for her kind assistance with the XPS measurements. V. O. is an ALN fellow.

\section{Notes and references}

\author{
1 J. A. Turner, Science, 2004, 305, 972-974.
}


2 I. Roger, M. A. Shipman and M. D. Symes, Nat. Rev. Chem., 2017, 1, 003.

3 H. N. Nong, L. Gan, E. Willinger, D. Teschner and P. Strasser, Chem. Sci., 2014, 5, 2955-2963.

4 Z.-P. Wu, X. F. Lu, S.-Q. Zang and X. W. Lou, Adv. Funct. Mater., 2020, 30, 1910274.

5 F. Lyu, Q. Wang, S. M. Choi and Y. Yin, Small, 2019, 15, 1804201.

6 C. C. L. McCrory, S. Jung, J. C. Peters and T. F. Jaramillo, J. Am. Chem. Soc., 2013, 135, 16977-16987.

7 Y. Lee, J. Suntivich, K. J. May, E. E. Perry and Y. Shao-Horn, J. Phys. Chem. Lett., 2012, 3, 399-404.

8 C. Feng, M. B. Faheem, J. Fu, Y. Xiao, C. Li and Y. Li, ACS Catal., 2020, 10, 4019-4047.

9 H. Bandal, K. K. Reddy, A. Chaugule and H. Kim, J. Power Sources, 2018, 395, 106-127.

10 F. Song, M. M. Busch, B. Lassalle-Kaiser, C.-S. Hsu, E. Petkucheva, M. Bensimon, H. M. Chen, C. Corminboeuf and X. Hu, ACS Cent. Sci., 2019, 5, 558-568.

11 S. Zou, M. S. Burke, M. G. Kast, J. Fan, N. Danilovic and S. W. Boettcher, Chem. Mater., 2015, 27, 80118020.

12 M. Gong and H. Dai, Nano Res., 2015, 8, 23-39.

13 F. Dionigi, Z. Zeng, I. Sinev, T. Merzdorf, S. Deshpande, M. B. Lopez, S. Kunze, I. Zegkinoglou, H. Sarodnik, D. Fan, A. Bergmann, J. Drnec, J. F. de Araujo, M. Gliech, D. Teschner, J. Zhu, W.-X. Li, J. Greeley, B. R. Cuenya and P. Strasser, Nat. Commun., 2020, 11, 1-10.

14 Layered double hydroxides, ed. X. Duan and D. G. Evans, Springer, Berlin, New York, 2005.

15 G. Abellán, C. Martí-Gastaldo, A. Ribera and E. Coronado, Acc. Chem. Res., 2015, 48, 1601-1611.

16 G. Abellán, J. A. Carrasco and E. Coronado, Layered double hydroxide nanocomposites based on carbon nanoforms, in Layered Double Hydroxide Polymer Nanocomposites, ed. S. Thomas and S. Daniel, Woodhead Publishing, Elsevier, Kidlington, 2020, pp. 411-460.

17 A. Gomes, D. Cocke, D. Tran and A. Baksi, in Energy Technology 2015: Carbon Dioxide Management and Other Technologies, ed. A. Jha, C. Wang, N. R. Neelameggham, D. P. Guillen, L. Li, C. K. Belt, R. Kirchain, J. S. Spangenberger, F. Johnson, A. J. Gomes, A. Pandey and P. Hosemann, Springer International Publishing, Cham, 2016, pp. 309-316.

18 F. Li and X. Duan, Aplications of layered double hydroxides, in Layered Double Hydroxides, ed. X. Duan and D. G. Evans, Springer, Berlin, New York, 2005.

19 Q. Wang and D. O'Hare, Chem. Rev., 2012, 112, 41244155.

20 A. Seijas-Da Silva, R. Sanchis-Gual, J. A. Carrasco, V. Oestreicher, G. Abellán and E. Coronado, Batteries Supercaps, 2020, 3, 499-509.

21 F. Dionigi and P. Strasser, Adv. Energy Mater., 2016, 6, 1600621.

22 Y. Wang, D. Yan, S. El Hankari, Y. Zou and S. Wang, Adv. Sci., 2018, 5, 1800064.
23 H. Yi, S. Liu, C. Lai, G. Zeng, M. Li, X. Liu, B. Li, X. Huo, L. Qin, L. Li, M. Zhang, Y. Fu, Z. An and L. Chen, Adv. Energy Mater., 2021, 11, 2002863.

24 F. Song and X. Hu, Nat. Commun., 2014, 5, 4477.

25 J. A. Carrasco, A. Harvey, D. Hanlon, V. Lloret, D. McAteer, R. Sanchis-Gual, A. Hirsch, F. Hauke, G. Abellán, J. N. Coleman and E. Coronado, Chem. Commun., 2019, 55, 3315-3318.

26 J. M. Gonçalves, P. R. Martins, L. Angnes and K. Araki, New J. Chem., 2020, 44, 9981-9997.

27 P. Li, X. Duan, Y. Kuang, Y. Li, G. Zhang, W. Liu and X. Sun, Adv. Energy Mater., 2018, 8, 1703341.

28 X. Zhang, Y. Zhao, Y. Zhao, R. Shi, G. I. N. Waterhouse and T. Zhang, Adv. Energy Mater., 2019, 9, 1900881.

29 J. A. Carrasco, A. S. Da Silva, V. Oestreicher, J. Romero, B. G. Márkus, F. Simon, B. J. C. Vieira, J. C. Waerenborgh, G. Abellán and E. Coronado, Chem. - Eur. J., 2020, 26, 6504-6517.

30 J. A. Carrasco, R. Sanchis-Gual, A. Seijas-Da Silva, G. Abellán and E. Coronado, Chem. Mater., 2019, 31, 67986807.

31 D. Zhou, P. Li, X. Lin, A. McKinley, Y. Kuang, W. Liu, W.-F. Lin, X. Sun and X. Duan, Chem. Soc. Rev., 2021, 50, 8790-8817.

32 P. J. Sideris, F. Blanc, Z. Gan and C. P. Grey, Chem. Mater., 2012, 24, 2449-2461.

33 G. Abellán, E. Coronado, C. Martí-Gastaldo, J. Waerenborgh and A. Ribera, Inorg. Chem., 2013, 52, 10147-10157.

34 S. S. C. Pushparaj, C. Forano, V. Prevot, A. S. Lipton, G. J. Rees, J. V. Hanna and U. G. Nielsen, J. Phys. Chem. C, 2015, 119, 27695-27707.

35 T. Kawabata, N. Fujisaki, T. Shishido, K. Nomura, T. Sano and K. Takehira, J. Mol. Catal. A: Chem., 2006, 253, 279289.

36 G. Abellán, E. Coronado, C. Martí-Gastaldo, E. PinillaCienfuegos and A. Ribera, J. Mater. Chem., 2010, 20, 7451.

37 S. Jaśkaniec, C. Hobbs, A. Seral-Ascaso, J. Coelho, M. P. Browne, D. Tyndall, T. Sasaki and V. Nicolosi, Sci. Rep., 2018, 8, 1-8.

38 R. L. Doyle, I. J. Godwin, M. P. Brandon and M. E. G. Lyons, Phys. Chem. Chem. Phys., 2013, 15, 1373713783.

39 Y. Gorlin, C.-J. Chung, J. D. Benck, D. Nordlund, L. Seitz, T.-C. Weng, D. Sokaras, B. M. Clemens and T. F. Jaramillo, J. Am. Chem. Soc., 2014, 136, 4920-4926.

40 M. Görlin, P. Chernev, J. Ferreira de Araújo, T. Reier, S. Dresp, B. Paul, R. Krähnert, H. Dau and P. Strasser, J. Am. Chem. Soc., 2016, 138, 5603-5614.

41 V. Oestreicher and M. Jobbágy, Chem. - Eur. J., 2019, 25, 12611-12619.

42 V. Oestreicher, I. Fábregas and M. Jobbágy, J. Phys. Chem. C, 2014, 115, 30274-30281.

43 G. Centi and F. Vazzana, Catal. Today, 1999, 53, 683-693.

44 M. Schwidder, M. Kumar, K. Klementiev, M. Pohl, A. Bruckner and W. Grunert, J. Catal., 2005, 231, 314-330. 
45 A. C. Heredia, M. I. Oliva, U. Agú, C. I. Zandalazini, S. G. Marchetti, E. R. Herrero and M. E. Crivello, J. Magn. Magn. Mater., 2013, 342, 38-46.

46 M. C. Biesinger, B. P. Payne, A. P. Grosvenor, L. W. M. Lau, A. R. Gerson, R. St. and C. Smart, Appl. Surf. Sci., 2011, 257, 2717-2730.

47 Y. H. Wen, H. M. Zhang, P. Qian, H. T. Zhou, P. Zhao, B. L. Yi and Y. S. Yang, Electrochim. Acta, 2006, 51, 37693775 .

48 V. Oestreicher, D. Hunt, R. Torres-Cavanillas, G. Abellán, D. A. Scherlis and M. Jobbágy, Inorg. Chem., 2019, 58, 9414-9424.

49 V. Oestreicher, G. Abellán and E. Coronado, Phys. Status Solidi RRL, 2020, 14, 2000380.

50 V. Oestreicher, C. Dolle, D. Hunt, M. Fickert and G. Abellán, Nano Mater. Sci., 2020, DOI: 10.1016/ j.nanoms.2020.12.004.

51 J. A. Carrasco, G. Abellán and E. Coronado, J. Mater. Chem. C, 2018, 6, 1187-1198.

52 G. Abellán, E. Coronado, C. J. Gómez-García, C. MartíGastaldo and A. Ribera, Polyhedron, 2012, 52, 216-221217.

53 G. Abellán, J. A. Carrasco and E. Coronado, Inorg. Chem., 2013, 52, 7828-7830.

54 Y. Du and D. O'Hare, J. Phys. Chem. Solids, 2008, 69, 10401043.
55 B. Wu, Z. Yang, X. Dai, X. Yin, Y. Gan, F. Nie, Z. Ren, Y. Cao, Z. Li and X. Zhang, Dalton Trans., 2021, 50, 1254712554.

56 Y. Qiu, Q. Jia, S. Yan, B. Liu, J. Liu and X. Ji, ChemSusChem, 2020, 13, 4911-4915.

57 W. Huo, L. Li, Y. Zhang, J. Li, Q. Xu, B. Zhang, L. Zhang and X. Li, Front. Mater., 2019, 6, 154.

58 B.-J. Kim, E. Fabbri, D. F. Abbott, X. Cheng, A. H. Clark, M. Nachtegaal, M. Borlaf, I. E. Castelli, T. Graule and T. J. Schmidt, J. Am. Chem. Soc., 2019, 541, 5231-5240.

59 M. Grdeń, M. Alsabet and G. Jerkiewicz, ACS Appl. Mater. Interfaces, 2012, 4, 3012-3021.

60 L. Trotochaud, S. L. Young, J. K. Ranney and S. W. Boettcher, J. Am. Chem. Soc., 2014, 136, 6744-6753.

61 J. J. Bravo-Suárez, E. A. Páez-Mozo and S. T. Oyama, Quím. Nova, 2004, 27, 601-614.

62 V. Oestreicher, I. Fábregas and M. Jobbágy, J. Phys. Chem. C, 2014, 118, 30274-30281.

63 Z. Wang, P. Fang, P. Kumar, W. Wang, B. Liu and J. Li, Nanomaterials, 2019, 9, 807.

64 L. Dang, H. Liang, J. Zhuo, B. K. Lamb, H. Sheng, Y. Yang and S. Jin, Chem. Mater., 2018, 30, 4321-4330.

65 C. J. Wang, Y. A. Wu, R. M. J. Jacobs, J. H. Warner, G. R. Williams and D. O'Hare, Chem. Mater., 2011, 23, 171180. 